\title{
Genetic variability and spatial distribution in small geographic scale of Aedes aegypti (Diptera: Culicidae) under different climatic conditions in Northeastern Brazil
}

Lizandra Makowski Steffler ${ }^{1}$, Silvio Santana Dolabella ${ }^{1,2}$, Paulo Eduardo Martins Ribolla ${ }^{3}$, Carine Spenassatto Dreyer ${ }^{3}$, Edilson Divino Araújo ${ }^{4,5}$, Rosane Gomes Oliveira ${ }^{5}$, Walter Fabrício Silva Martins ${ }^{6}$ and Roseli La Corte ${ }^{1,2^{*}}$ (D)

\begin{abstract}
Background: The study of the genetic structure of Aedes aegypti is essential to understanding their population dynamics as well as for the analysis of factors responsible for their resistance and ecological adaptation. The use of molecular markers in identifying differences amongst populations of Ae. aegypti in different geographical areas as well as the temporal variation of the vector populations has contributed to the improvement of vector control strategies. The present study aims to determine the genetic variability of Ae. aegypti populations in a small geographical area (state of Sergipe, Northeastern Brazil) by means of inter-simple sequence repeat (ISSR) and single nucleotide polymorphism (SNP) molecular markers.

Results: ISSR markers revealed a more heterogeneous pattern of genetic diversity among the populations with an expected heterozygosity $\left(H_{\mathrm{E}}\right)$ ranging from $0.261 \pm 0.03$ to $0.120 \pm 0.032$, while a similar trend was detected through SNPs across populations with an $H_{E}$ between $0.375 \pm 0.054$ and $0.269 \pm 0.042$. The population's genetic differentiation assessed with ISSR and SNP markers indicated a very low structuring among the populations with the highest diversity observed within the populations $72 \%$ (ISSR) and $92 \%$ (SNP). Clustering analysis also suggested little variation among populations: the seven populations were grouped into only three ISSR clusters and a single panmictic group based on SNP markers. The present study identified a close relationship between the populations, which probably results mainly from passive gene flow between mosquitoes from distinct geographic regions, influenced by humans commuting along roads.
\end{abstract}

Conclusions: There was an intense migration of mosquitos across municipalities, leading to a potential increase in risk of arbovirus and insecticide resistance associated-alleles spreading between mosquito populations.

Keywords: ISSR-PCR, Single nucleotide polymorphism, Entomological surveillance, Vector control, Zika, Dengue, Chikungunya, Arboviruses

\footnotetext{
* Correspondence: rlacorte@ufs.br

'Programa de Pós-Graduação em Biologia Parasitária, Universidade Federal de Sergipe, Av. Mal Rondon s/n, CEP 49.100-000 São Cristóvão, Sergipe, Brazil ${ }^{2}$ Departamento de Morfologia, Universidade Federal de Sergipe, Av. Mal Rondon s/n, CEP 49.100-000 São Cristóvão, Sergipe, Brazil

Full list of author information is available at the end of the article
} 


\section{Background}

Aedes aegypti is a major vector of several human arboviruses including Yellow fever, Dengue fever, Chikungunya and Zika virus in several tropical and sub-tropical countries. In Brazil, the mosquito has been reported in all states and the number of cities where it is found has increased with time [1]. The prevalence of this vector is alarming as it is the main factor related to Dengue fever, Zika and Chikungunya epidemics. It also reveals the failure of the current vector control strategy held by the National Dengue Control Program, based on breeding site elimination, which has prompted the search for new control strategies [2-4].

The discovery of genetic markers has facilitated the following-up of groups of genes or of genome segments related to a phenotype of interest. Studies based on biological markers such as isoenzymes, random amplified polymorphic DNA (RAPD), restriction fragment length polymorphism (RFLP), single-strand conformation polymorphism (SSCP), single nucleotide polymorphism (SNPs) and microsatellites have resulted in the construction of genetic maps for Ae. aegypti [5]. In spite of this, a limited number of new microsatellites have been identified in $A e$. aegypti [6-9]. Studies on new microsatellite loci in Anopheles gambiae, Culex quinquefasciatus and Ae. aegypti have shown they are more abundant (with regards to the genome frequency percentage) in An. gambiae (0.75\%) and less abundant in Ae. aegypti (0.109 \%) [10].

The inter-simple sequence repeat-polymerase chain reaction (ISSR-PCR) technique amplifies regions between microsatellites, using core microsatellite sequences as primers. Two important characteristics are observed when using ISSR-PCR: (i) high levels of polymorphism, which is particularly important for geographically small-scale intraspecific studies that aim to genetically identify different populations of a species; and (ii) the increased annealing temperature of the primers, which leads to high reproducibility of the DNA band pattern [11].

Understanding the genetics of Ae. aegypti is essential in order to gain an in-depth understanding of population dynamics, factors responsible for resistance to insecticides and ecological adaptation [12]. Molecular markers can aid the identification of geographical and temporal differences amongst Ae. aegypti populations, contributing to the improvement of mosquito vector control strategies [13-15]. Investigation of the Ae. aegyti genome indicates that SNP frequency is often dependent on gene function [16]. The partial sequencing of seven $A e$. aegypti genes revealed the existence of 53 polymorphic SNPs, eight of these were used to outline the population structure of three Ae. aegypti populations, proving to be highly polymorphic markers that are useful for population studies [17].
The aim of the present study was to determine the genetic variability of Ae. aegypti populations on a small geographical scale with high spatial heterogeneity by means of SNP and ISSR molecular markers. The study included cities located in humid tropical, agreste and semiarid areas in the state of Sergipe, northeastern Brazil. The results of this study will not only contribute to the vector biology knowledge base, but may even be suitable for supporting new approaches of mosquito control, and furthering studies of the main factors related to the genetic differences observed.

\section{Methods \\ Mosquito samples and DNA extraction}

The study was carried out in the state of Sergipe, northeastern Brazil $\left(9^{\circ} 31^{\prime} \mathrm{S}\right.$ to $11^{\circ} 33^{\prime} \mathrm{S}$ and $36^{\circ} 25^{\prime} \mathrm{W}$ to $\left.38^{\circ} 14^{\prime} \mathrm{W}\right)$, covering an area of $21,918 \mathrm{~km}^{2}$ and including $2,068,017$ inhabitants [18]. The distribution of annual precipitation in this state is highly heterogeneous, with a decreasing gradient from the shoreline's humid tropical climate and annual precipitation of over $1600 \mathrm{~mm}$, stretching through to the agreste (transition zone) towards the sertão (semiarid climate), where annual precipitation below $500 \mathrm{~mm}$ has been recorded. The rainy period in this state is concentrated between April and August, with peaks in May, June and July [19].

Aedes aegypti was sampled from 7 locations in Sergipe, including Carira (CA), Pinhão (PI) and Neópolis (NEO) (Agreste), Canindé de São Francisco (CSF) (semiarid), Maruim (MA), Aracaju (ARA) and Umbaúba (UMB) (humid tropical) (Fig. 1). A hundred ovitraps were installed in each city, except the state capital Aracaju, where only one neighborhood was sampled with 30 ovitraps. The selection of the cities aimed to include most of the state, taking into consideration the different climatic types (humid tropical, agreste and semiarid). The longest distance registered was between the cities of Canindé de São Francisco and Umbaúba (road= $243 \mathrm{~km} /$ linear $=193 \mathrm{~km}$ ) and the shortest one was between Carira and Pinhão ( $\mathrm{road}=30 \mathrm{~km} / \mathrm{linear}=$ $20 \mathrm{~km}$ ). Although Carira and Pinhão are geographically very close, they were treated as distinct populations since they showed different levels of resistance to temephos (data not shown) in the susceptibility test performed for these populations in our laboratory.

Rearing of the Ae. aegypti populations was held in an acclimated area with monitored temperature and humidity (temperature at $26{ }^{\circ} \mathrm{C} \pm 2{ }^{\circ} \mathrm{C}$, air relative humidity at $70 \% \pm 20{ }^{\circ} \mathrm{C}$ and 12 -h photoperiod). For each city, 20 three-day-old Ae. aegypti females from the wild population were analyzed, adding up to a total of 140 individuals. The genomic DNA was extracted from the whole body according to a published method [20], and stored at $-20{ }^{\circ} \mathrm{C}$. 


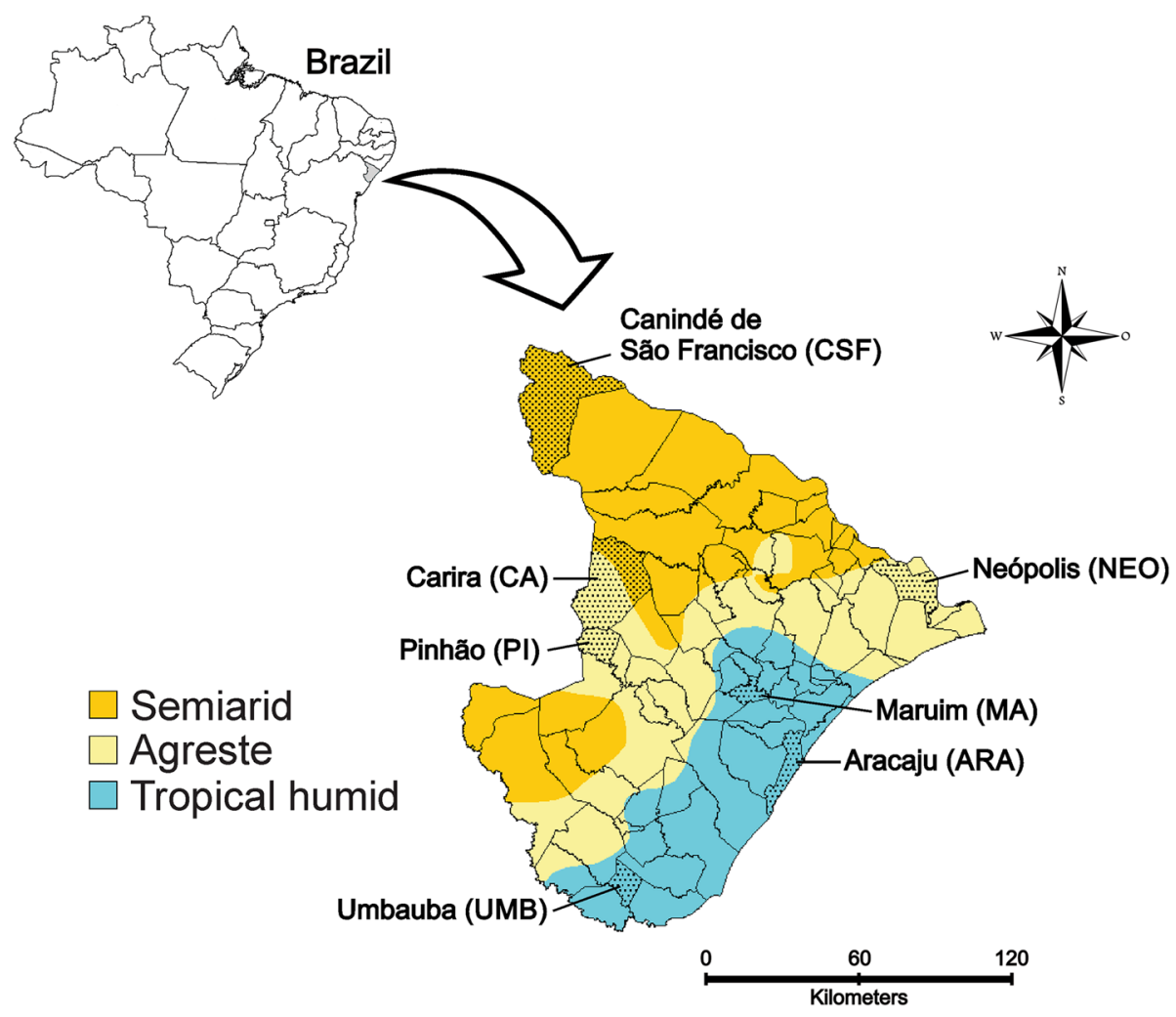

Fig. 1 Map of the state of Sergipe (Brazil) showing the locations of the cities selected for the study

\section{Genetic analysis \\ ISSR genotyping}

Two primers designated $(\mathrm{CA})_{8} \mathrm{RY}$ and $(\mathrm{GA})_{8} \mathrm{RY}$ were used. The primers possess one random purine $(\mathrm{R})$ and pyrimidine (Y) anchored in the $3^{\prime}$ portion. The premix for PCR consisted of a reaction of $15 \mu \mathrm{l}$, containing $50 \mathrm{ng}$ genomic DNA, RB 10× buffer (10 mM Tris- $\mathrm{HCl}$ pH 8.5, $50 \mathrm{mM}$ $\left.\mathrm{KCl}, 1.5 \mathrm{mM} \mathrm{MgCl}_{2}\right), 1.5 \mathrm{U}$ of Taq polymerase $(5 \mathrm{U} / \mu \mathrm{l})$ (Invitrogen, Carlsbad, CA, USA), $0.2 \mathrm{mM}$ of dNTPs and $1 \mu \mathrm{M}$ of the primers $(\mathrm{CA})_{8} \mathrm{RY}$ or $(\mathrm{GA})_{8} \mathrm{RY}$. Samples were processed in duplicate as follows: denaturation at $95{ }^{\circ} \mathrm{C}$ for $5 \mathrm{~min}$, followed by 39 cycles of denaturation at $95{ }^{\circ} \mathrm{C}$ for $30 \mathrm{~s}$, annealing at $47.5{ }^{\circ} \mathrm{C}$ and $45.2{ }^{\circ} \mathrm{C}$ for $30 \mathrm{~s}$ for the primer $(\mathrm{CA})_{8} \mathrm{RY}$ and $(\mathrm{GA})_{8} \mathrm{RY}$, respectively, and extension at $72{ }^{\circ} \mathrm{C}$ for $2 \mathrm{~min}$. A final extension step at $72{ }^{\circ} \mathrm{C}$ for $5 \mathrm{~min}$ was also included. The amplification product underwent $1 \%$ agarose gel electrophoresis using ethidium bromide as colorant. The selection of the bands was carried out with the aid of the GelAnalyser v. 2010a software (http:// www.gelanalyzer.com) and reproducibility of the gel comparison results obtained from the amplification in duplicate, with each band considered as a locus.

\section{SNPs genotyping}

For the characterization of populations, we used 9 SNP markers related to the genes ef2 (elongation factor), aeimuc1 (mucin-like protein), nak (sodium/potassium channel), pgk (phosphoglycerate kinase), apolp-2 (apolipophorin II), ferh (ferritin heavy chain), cyp9j2 (cytocrome P450), tsf (transferrin) and chym (chymotrypsin), which have previously been selected for the population study of Ae. aegypti in Brazil [17]. These genes were chosen because they are randomly distributed in the Ae. aegypti genome.

The DNA of each mosquito underwent amplification by quantitative real-time PCR using the StepOnePlus ${ }^{\text {TM }}$ v. 2.1 platform (Thermo Fisher Scientific, Waltham, MA, USA) using 96-well optical plate and TaqMan ${ }^{\bullet}$ system (Thermo Fisher Scientific, Waltham, MA, USA) for the allelic discrimination. The initial amplification conditions were $25^{\circ} \mathrm{C}$ for $30 \mathrm{~s}$ (equipment pre-reading); denaturation at $95^{\circ}$ $\mathrm{C}$ for $3 \mathrm{~min}$, followed by 40 cycles of denaturation at $95{ }^{\circ} \mathrm{C}$ for $3 \mathrm{~s}$, annealing/extension at $60{ }^{\circ} \mathrm{C}$ for $30 \mathrm{~s}$ and a final step at $25{ }^{\circ} \mathrm{C}$ for $30 \mathrm{~s}$. SNPs were automatically identified with the help of the StepOnePlus ${ }^{\mathrm{TM}}$ v. 2.1 platform software (Thermo Fisher Scientific, Waltham, MA, USA).

\section{Data analysis}

The index of genetic diversity and the molecular variance (AMOVA) were carried out using GenAlEx [21]. Genetic differentiation among populations was estimated through a Bayesian analysis using STRUCTURE 2.3 [22]. In this analysis, all 140 individuals were probabilistically assigned 
to a single cluster without using the known geographic sample collection location. To identify the optimal number of clusters $(K)$, with the assumption that the sampled belong to an unknown number of $K$ genetically distinct clusters, twenty independent runs were conducted for each $K$ value (ranging from $K=1$ to $K=10$ ), with 5000 interactions and 50,000 replications. The most likely $K$ value was calculated for each run with the log likelihood $[\operatorname{LnP}(\mathrm{D})]$ method and results compiled using CLUMPP [23]. Population structure was also evaluated with discriminant analysis of principal components (DAPC) using the adegenet $\mathrm{R}$ package [24]. To identify an optimal number of clusters for the DAPC clustering, K-means values were sequentially tested and then compared using Bayesian information criterion (BIC), with the lowest value of BIC used as the likely number of population clusters.

\section{Results}

\section{Genetic diversity}

\section{ISSR markers}

For this analysis, 17 bands were selected for the primer $(\mathrm{CA})_{8} \mathrm{RY}$, which varied between 450 and 2230 base pairs (bp) and 13 bands for the primer $(\mathrm{GA})_{8} \mathrm{RY}$, which varied between 350 and $1700 \mathrm{bp}$, resulting in a total of 30 bands (Additional file 1: Table S1; Additional file 2: Figure S1), of which 29 were polymorphic. The highest number of bands was observed in the population CA with a total of 25 bands (with 3 private alleles), while the lowest number of bands was detected in NEO with only 19 markers (Fig. 2). Across populations, a significant difference was detected in the expected heterozygosity which ranged from $H_{\mathrm{E}}=0.261$ \pm 0.03 to $H_{\mathrm{E}}=0.120 \pm 0.032$ (Fig. 2 and Additional file 1: Table S1), with the percentage of polymorphic loci varying between 73.33 and $43.33 \%$ in mosquitoes from CSF and PI, respectively.

\section{SNP markers}

Across all populations, the 7 loci studied were polymorphic in $95.25 \%$ of the locus/locations, with the exception of 3 loci; $p g k, n a k$ and ferh which were monomorphic in CA, PI and NEO, respectively (Additional file 3: Table S2; Additional file 4: Figure S2). Among the 7 loci, a higher genetic diversity was observed for ferh $\left(H_{E}=0.750\right)$ in PI where a distinct pattern of $H_{E}$ was detected between

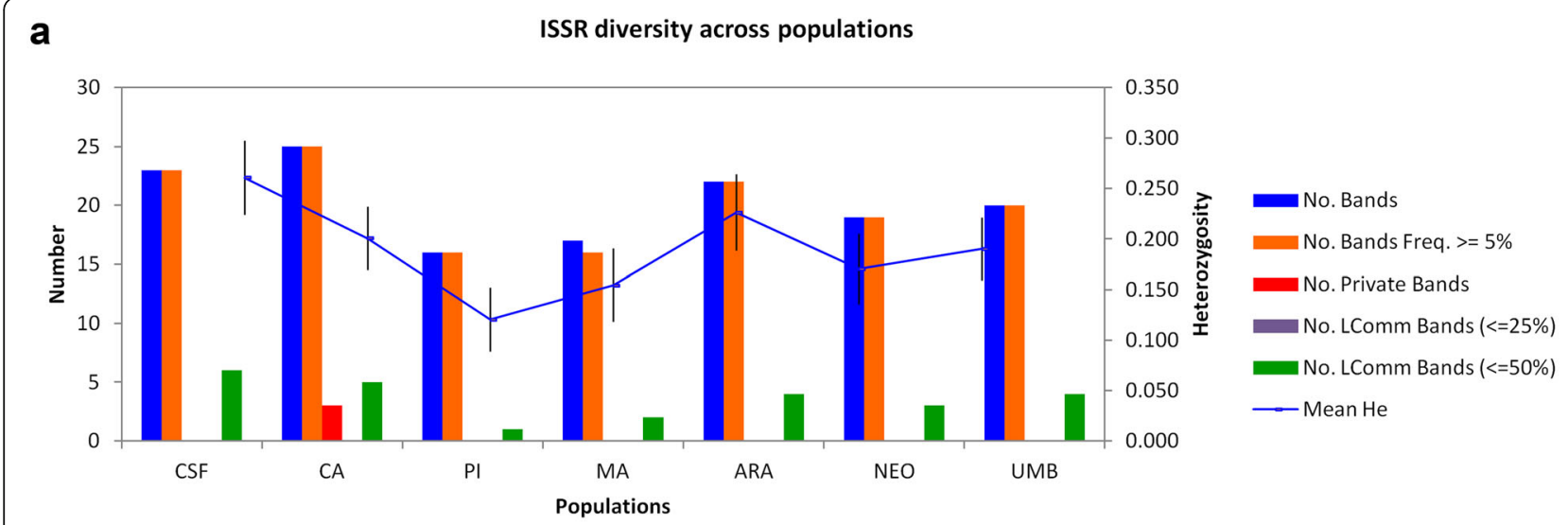

b

SNPs diversity across Populations

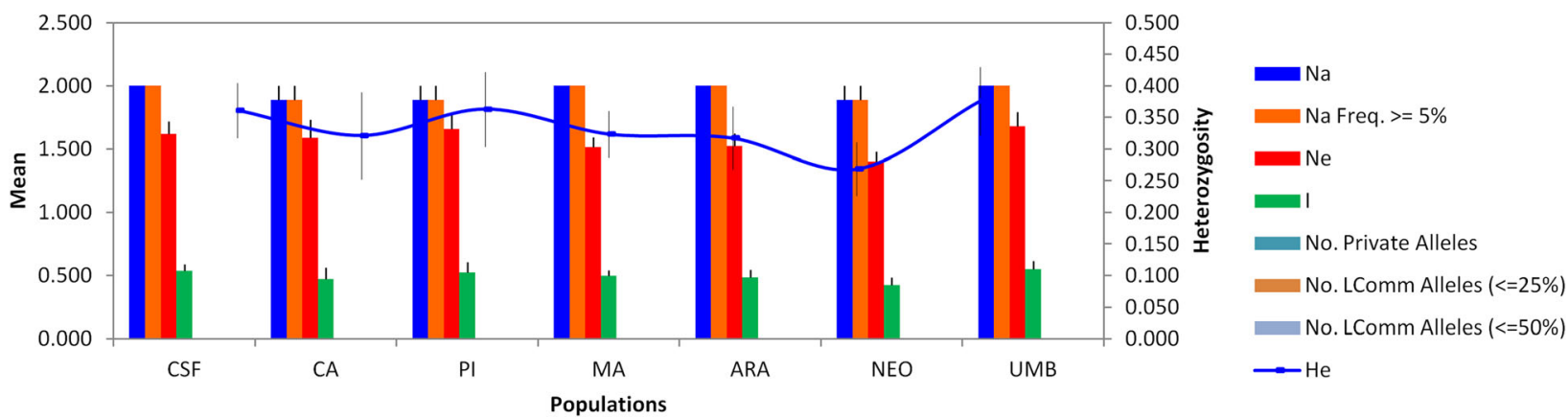

Fig. 2 Characterization of genetic diversity in Aedes aegypti mosquitoes from Sergipe, Brazil. a and $\mathbf{b}$ correspond to genetic diversity index based on ISSR and SNPs, respectively. CSF: Canindé de São Francisco; CA: Carira; Pl: Pinhão; MA: Maruim; ARA: Aracaju; NEO: Neópolis; UMB: Umbaúba; No. Bands: No. of different $b$ ands; No. private bands: No. of bands unique to a single population; No. LComm Bands: No. of locally common bands; Na: No. of different alleles; Ne: No. of effective alleles; I: Shannon's information index; He: expected heterozygosity 
populations (Additional file 3: Table S2, Additional file 5: Table S3). Amongst the populations, a similar index of genetic variability (Fig. 2) was observed, with the observed heterozygosis ranging from $0.375 \pm 0.054$ to $0.269 \pm 0.042$ in samples from PI and NEO, respectively.

In all 60 instances where polymorphic locus/populations were tested for locus Hardy-Weinberg (HW) equilibrium, significant deviation from HW equilibrium was not detected, with $P>0.05$ (Additional file 5: Table S3). Nevertheless, for 6 loci, a significant departure from HW was observed, with $P<0.01$; apolp-2 (CA), ferh (PI), nak and chym (NEO) and ef2 and aelmuc1 (UMB). In all 6 loci, a deficit of heterozygosity was observed (Additional file 3: Table S2; Additional file 6: Tables S4 and S5).

\section{Genetic structure}

The populations' genetic differentiation was assessed using ISSR and SNP markers across all 7 populations. The genetic distances among populations ranged from 0.033 (NEO and MA) to 0.120 (ARA and UMB) for ISSR markers (Additional file 7: Figure S3), while for SNPs (Additional file 7: Figure S3), the highest genetic distance (0.145) was observed between PI and NEO and the lowest (0.008) between MA and ARA. Through AMOVA, the highest diversity within the population, $72 \%$ (ISSR) and $92 \%$ (SNP), was observed for both markers. In population and geographical clusters, a very low differentiation of 0 and $28 \%$ for ISSR was detected, and $4 \%$ in each category for SNP markers.

The small genetic differentiation suggested by AMOVA analysis was also suggested by DAPC and STRUCTURE analysis, indicating that the populations studied are very close related. For ISSR markers, DAPC and STRUCTURE analysis indicated the presence of only 2 and 3 clusters, respectively (Figs. 3a and 4). On the other hand, when using the SNP markers, both methods indicated an absence of differentiation among populations: all populations were grouped within a single cluster by DAPC (Fig. 3b) and had a very low and unstable delta $K$-value through the STRUCTURE analysis (Additional file 8: Figure S4). For both markers, no significant association between genetic and geographical distance was observed using the Mantel test (Additional file 9: Figure S5).

\section{Discussion}

Based on both genetic markers, ISSR and SNPs a high level of genetic diversity was identified, with most of the markers in all seven populations analyzed being polymorphic. Nevertheless, our analysis indicated a different diversity trend across populations: with ISSR markers significant genetic variability was observed whereas with SNPs, no significant variation among the locations was observed. This distinct pattern of diversity was somewhat expected and could reflect their genetic properties, as ISSR is dominant and can amplify coding or neutral genomic regions while SNPs are located within specific expressed loci, which are more conserved and stable genomic regions. As such, the ISSR markers located in neutral genomic regions could be more diverse and reflect the populations' recent dynamic events, such as variations in the effective population size, bottle necks and migration. Many studies have shown large populations experience more mutations than those with a small effective population size [25], while bottle necks (reductions in effective population size) reduce most-recent common ancestor (MRCA) alleles, which in turn reduces the average level of variability [26].

The genetic variation detected by ISSR markers might also be linked to the different climate characteristics that vary strongly within the small geographical area of Sergipe State. In this region, the climate is characterized tropical humid, agreste and semiarid. Rainfall and relative humidity across these regions ranges from $1355 \mathrm{~mm}$ to $700 \mathrm{~mm}$ and from 80 to $65 \%$, respectively [27]. Ecological studies of Ae. aegytpi populations from Paraíba State, Brazil, showed that, under experimental conditions with temperatures ranging from 25 to $32{ }^{\circ} \mathrm{C}$, variation in climatic conditions was reflected in changes to mosquito larval development, longevity, fecundity, eggs quantity and body size [28, 29]. Consequently, the genetic variation observed among Sergipe's populations could be linked to the ecological zone from where samples were collected.

It is also possible that the distinct genetic diversity between the populations might be associated with differences in predominance/availability of breeding sites in each city, i.e. predominance of laundry sinks in Aracaju [30] and water tanks (cisterns) in Pinhão. The increased availability of these breeding sites could result in distinct mosquito population densities and inbreeding, and then directly impact a population's genetic diversity.

On the other hand, the similar genetic diversity observed with SNP markers across the populations/geographic groups might reflect the markers' location in the coding regions of the genes analyzed, resulting in a lower mutation rate. It is also possible that these markers are behaving as neutral markers since they might not be linked with the possible selection pressure imposed by vector control interventions. If selection pressure was acting on one of these loci, a significant difference in allele frequency among populations would be expected due to, for example, a positive selection or selective sweep, which changes allele frequency by increasing the frequency of derived alleles and then increasing a population's differentiation [31, 32]. For instance, the identification of selection footprints in insecticide resistance-associated alleles has been detected by identifying a reduction in genetic diversity [33, 34]. 


\section{a}

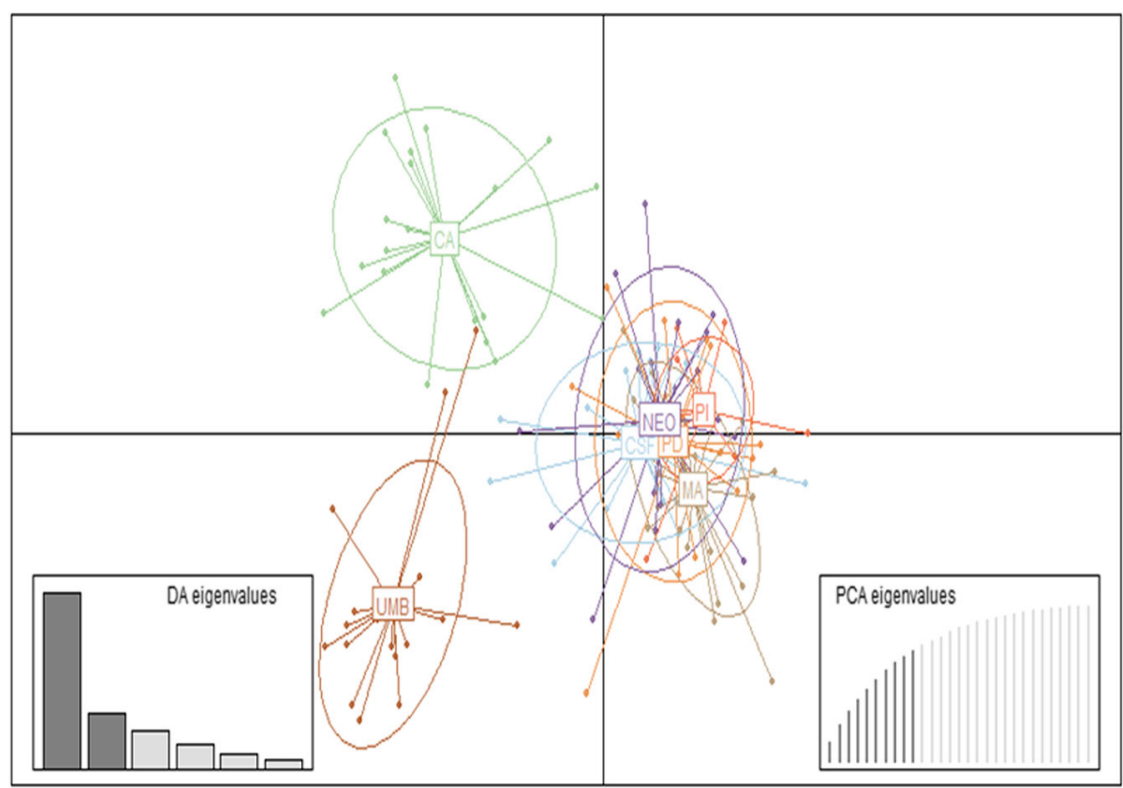

b

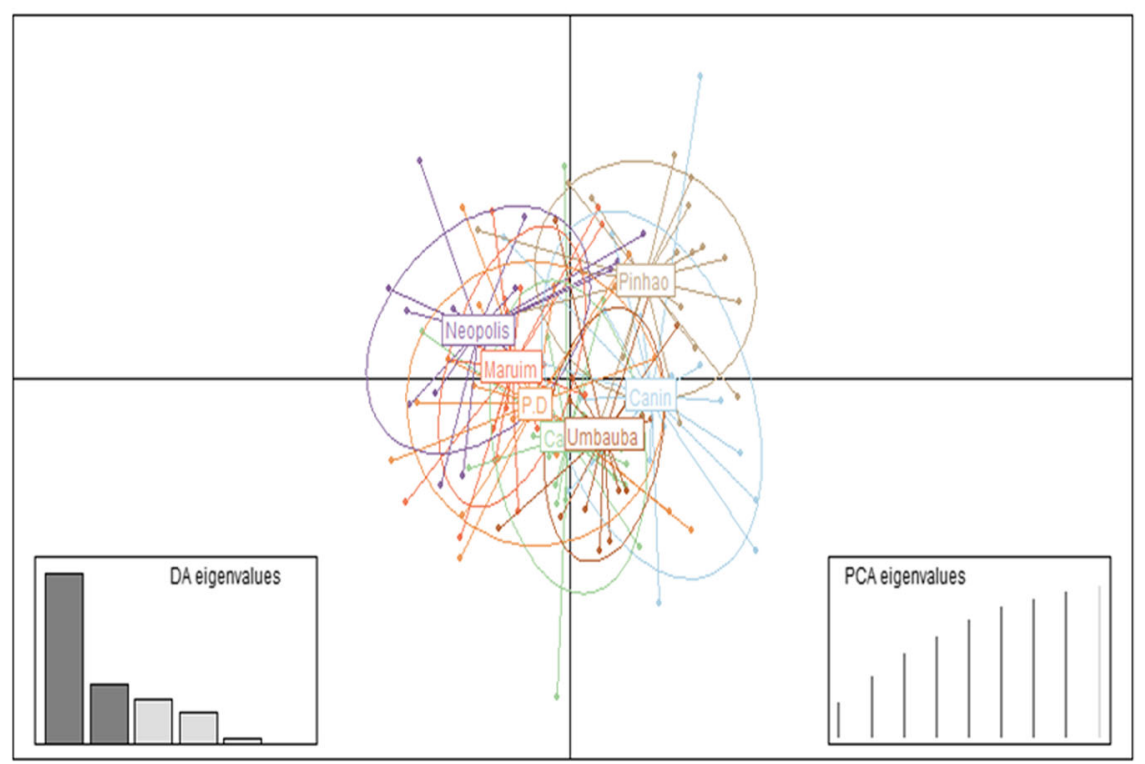

Fig. 3 Genetic differentiation estimates among the seven Ae. aegypti populations from Sergipe, Brazil. a, b First and second Principal Components of the DAPC using ISSR and SNP markers, respectively. Inferred populations clusters are indicated by ellipses, which model $95 \%$ of the corresponding variability. CSF: Canindé de São Francisco; CA: Carira; PI: Pinhão; MA: Maruim; ARA: Aracaju; NEO: Neópolis; UMB: Umbaúba

Even though most of the locus/population were under HW equilibrium, six markers (apolp-2, ferh, chym, nak, ef2 and aelmuc1) were not in HW equilibrium in one population each. Since HW disequilibrium did not occur in all population/locus, the possibility of null alleles due to problems in the annealing sites of the initiators used was discarded [35]. Nonetheless, these deviations in HW's equilibrium may be due to environmental differences among the populations' geographic location. For instance, although the geographic dimension evaluated here is small, it presents the relevant climatic differences such as a long drought period and high temperatures, which are characteristic of the semiarid region. In particular, the deviation from HW for the nak loci in Neopolis and monomorphism in Pinhão is especially relevant as it is located in the Sodium channel gene, which is the targetsite gene for pyrethroids and organochlorines insecticides [36]. The link between a possible selection sweep and this departure from HW equilibrium in these two populations has already been shown in other vector species such as Anopheles and Culex populations under insecticide selection pressure [37-39].

Both ISSR and SNP markers also indicated a high level of genetic similarity among populations, with the ISSR of 


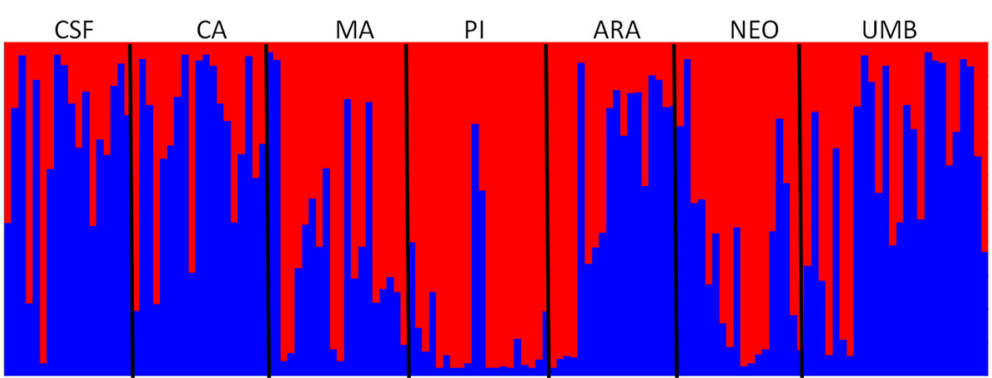

Fig. 4 Bayesian cluster analysis based on ISSR markers. Diagrammatic representation of population clusters for the most likely $K(K=2)$, where each vertical bar represents an individual and each colour represents the probability of belonging to one of the two clusters from Bayesian STRUCTURE analyses. CSF: Canindé de São Francisco; CA: Carira, PI: Pinhão; MA: Maruim; ARA: Aracaju; NEO: Neópolis; UMB: Umbaúba

seven populations grouped into three clusters whereas for SNPs, a single panmictic population was detected. Although both markers are in agreement with low differentiation among populations, the discordance between the number of clusters could result from inherent differences (dominant $v s$ codominant) and level of polymorphism and mutation rates (i.e. most SNPs are biallelic in contrast to the multiallelic properties of ISSR due to slippage mutation processes) [40]. Thus, these features could result in distinct heterozygosities and allele frequencies, which may have implications in the pattern of population relatedness observed [41]. Secondly, the number of markers analyzed by ISSR was around four times higher than the number of SNPs investigated indicating that due to a close relationship between the populations, a larger number of SNP markers might be required to detect the populations' differentiation using this marker.

The low differentiation in Sergipe's cities observed by molecular variance analysis (AMOVA) for the ISSR and SNP markers, with most of the variation detected within the populations, was also reported in Ae aegypti in northeastern Argentina and Uruguay. Around $89 \%$ of the diversity observed within populations in those studies was based on the same markers applied here [11]. Furthermore, a similar pattern of differentiation as Sergipe's population was also reported in mitochondrial DNA analysis which indicated the presence of only two haplotype groups of $A e$. aegypti circulating in Brazil [42, 43]. Nevertheless, the subpopulations reported in this study for the ISSR marker with three population clusters might not represent the two previous clusters described for mitochondrial DNA, since it has been reported that populations can have the same mitochondrial haplotype but be distinct when analyzed with nuclear SNPs [17, 44].

In addition to the likely impact of the introduction of Ae. aegypti with little genetic variation in Brazil as suggested by mitochondrial markers [42], it is also important to consider that the differentiation among Sergipe's population could reflect the intense gene flow mediated by the passive dispersion of mosquitoes, due to the intense traffic of vehicles between the cities. Our cluster analysis based on ISSR markers (Fig. 3a) also supports evidence of the possible impact of geographical distribution and route connection on a population's differentiation as the two more distinct clusters: $\mathrm{CA}$ and $\mathrm{UMB}$ correspond exactly to the most distant mosquito collection points, separated by $243 \mathrm{~km}$ (Fig. 1).

Paduan et al. [44] showed that regions connected by trade routes tend to have a lower genetic differentiation among Ae. aegypti populations when compared to areas that are more isolated. Additionally, Damal et al. [45] suggest that limited urbanization does not represent a strong enough barrier to stop the genetic flow. This suggests that passive movement has great importance in the mosquito's dispersion [46], as seen in our work, where road transportation may play an important role in interpopulation dispersion, thus intensifying the dispersion of insecticide resistance associated- alleles as well as potentially mediating a quicker spread of arboviruses such as Dengue, Zika and Chikungunya to nearby municipalities.

\section{Conclusions}

Our study showed that there is little differentiation among Sergipe's Ae. aegypti population, possibly reflecting intense gene flow mediated by the passive dispersion of mosquitoes, due to the intense traffic of vehicles among the cities. The results of this work could provide important assistance in the performance assessment of strategies for the control and handling of Ae. aegypti. Such actions have been the basis for the prevention of Dengue fever, Zika virus and Chikungunya epidemics with a focus on the control of both larval and adult stages chiefly with insecticide. That practice has generated resistance processes, compromising mosquito control and increasing the risk of epidemics every year. Thus, knowledge of the genetic structuring and population dynamics of the species is crucial as these genetically different populations may present differences concerning their vectorial capacity and vector competence. 


\section{Additional files}

Additional file 1: Table S1. ISSR genetic diversity across all seven Aedes aegypti populations from Sergipe, Brazil. (PDF 305 kb)

Additional file 2: Figure S1. Profile of the bands amplified with ISSR molecular marker for 20 samples of Aedes aegypti of the population of Pinhão. (PDF 196 kb)

Additional file 3: Table S2. Summary of SNP markers variation in different Sergipe populations of Aedes aegypti. (PDF 123 kb)

Additional file 4: Figure S2. Number of alleles detected per locuspopulation by SNP genotyping in seven Aedes aegypti populations from Sergipe Brazil. (PDF 73 kb)

Additional file 5: Table S3. Chi-square test and probabilities applied to infer Hardy-Weinberg departures for seven loci in Aedes aegypt mosquitoes. (PDF $64 \mathrm{~kb}$ )

Additional file 6: Tables S4 and S5. Matrix of Nei (1972) genetic distance for Sergipe's Aedes aegypti populations based on ISSR and SNP markers. (PDF $62 \mathrm{~kb}$ )

Additional file 7: Figure S3. Expected heterozygosity detected for seven SNP loci in Aedes aegypti populations. (PDF 74 kb)

Additional file 8: Figure S4. Clustering analysis using (A-D) Bayesian assignment of twenty runs for each $K, K=1$ to $K=10$. (PDF $90 \mathrm{~kb}$ )

Additional file 9: Figure S5. Pairwise relationship between genetic distance FST/(1- FST) vs geographical distance (km). (PDF 109 kb)

\section{Abbreviations}

aeimuc: Mucin-like protein; apolp-2: Apolipophorin II; ARA: Aracaju; BIC: Bayesian information criterion; CA: Carira; Chym: Chymotrypsin; CSF: Canindé de São Francisco; cyp9j2: Cytochrome P450; DAPC: Discriminant analysis of principal components; dNTP: Deoxynucleotide; ef2: Elongation factor; ferh: Ferritin heavy chain; $\mathrm{H}_{\mathrm{E}}$ : Expected heterozygosity; HW: Hardy-Weinberg; ISSR: Inter-simple sequence repeat; LnP(D): Log likelihood; MA: Maruim; nak: Sodium/potassium channel; NEO: Neópolis; PCR: Polymerase chain reaction; pgk: Phosphoglycerate kinase; PI: Pinhão; R: Purine; RAPD: Random amplified polymorphic; RFLP: Restriction fragment length polymorphism; SNP: Single nucleotide polymorphism; SSCP: Single-strand conformation polymorphism; tsf. Transferrin; UMB: Umbaúba; Y: Pyrimidine

\section{Acknowledgements}

Authors thank to Lydia Banfield for grammar and spelling review and Dr. Douglas F. R. Alves for the map preparation.

\section{Funding}

This project was carried out with resources from 1. Conselho Nacional de Pesquisa e Desenvolvimento (CNPq) and Fundação de Apoio à Pesquisa e Inovação Tecnológica do Estado de Sergipe (FAPITEC) - Edital 73/2009 Pronex Rede Dengue, 2. Conselho de Aperfeiçoamento de Pessoal do Ensino Superior (CAPES) - Edital 32/2010 Parasitologia Básica and 3. CAPES/FAPITEC - Edital 06/2012 PROMOB and masters' grant (FAPITEC) to Lizandra Makowski Steffler.

\section{Availability of data and materials}

The data supporting the findings of this study are included within the article and its additional files.

\section{Authors' contributions}

Conceived and designed the experiments: RLC, SSD, LMS, PEMR. Collected field samples: LMS, RLC, SSD. Performed the lab work: LMS, RLC, SSD, RGO, CSD, EDA. Analyzed the data: LMS, RLC, SSD, RGO, CSD, EDA, PEMR, WFSM. Contributed reagents/materials/analysis tools: RLC, SSD, EDA, PEMR, WFSM. Wrote the paper: LMS, RLC, SSD, WFSM. Critically revised manuscript: RLC, SSD, EDA, PEMR, WFSM. All authors read and approved the final version of the manuscript.

\section{Competing interests}

The authors declare that they have no competing interests.
Consent for publication

Not applicable.

Ethics approval and consent to participate

Not applicable.

\section{Author details}

${ }^{1}$ Programa de Pós-Graduação em Biologia Parasitária, Universidade Federal de Sergipe, Av. Mal Rondon s/n, CEP 49.100-000 São Cristóvão, Sergipe, Brazil. ${ }^{2}$ Departamento de Morfologia, Universidade Federal de Sergipe, Av. Mal Rondon s/n, CEP 49.100-000 São Cristóvão, Sergipe, Brazil.

${ }^{3}$ Departamento de Parasitologia, Universidade Estadual Júlio de Mesquita Filho, Rubião Junior, CP 510, CEP 18618-900 Botucatu, São Paulo, Brazil. ${ }^{4}$ Departamento de Biologia, Universidade Federal de Sergipe, Av. Mal Rondon s/n, CEP 49.100-000 São Cristóvão, Sergipe, Brazil. ${ }^{5}$ Programa de Pós-Graduação em Biotecnologia, Rede Nordeste de Biotecnologia, Universidade Federal de Sergipe, Av. Mal Rondon s/n, CEP 49.100-000 São Cristóvão, Sergipe, Brazil. 'Departamento de Biologia/CCBS, Universidade Estadual da Paraíba, R. Baraúnas 351, Campina Grande CEP 58.429-500, Paraíba, Brasil.

Received: 13 May 2016 Accepted: 22 September 2016

Published online: 04 October 2016

\section{References}

1. Souza-Santos C, Carvalho MS. Análise da distribuição espacial de larvas de Aedes aegypti na Ilha do Governador, Rio de Janeiro, Brasil. Cad Saude Publica. 2000:16:31-42.

2. Maciel-de-Freitas R, Aguiar R, Bruno RV, Guimarães MC, Lourenço-de-Oliveira $R$, Sorgine MHF, et al. Why do we need alternative tools to control mosquito-borne diseases in Latin America? Mem Inst Oswaldo Cruz. 2012;107:828-9.

3. Marteis LS, Steffler LM, Araújo KCGM, Santos RLC. Identificação e distribuição espacial de imóveis-chave de Aedes aegypti no bairro Porto Dantas, Aracaju, Sergipe, Brasil entre 2007 e 2008. Cad Saude Publica. 2013;29:368-78.

4. Paploski IA, Rodrigues MS, Mugabe VA, Kikuti M, Tavares AS, Reis MG, et al. Storm drains as larval development and adult resting sites for Aedes aegypti and Aedes albopictus in Salvador, Brazil. Parasit Vectors. 2016:9:419.

5. Clemons A, Haugen M, Flannery E, Tomchaney M, Kast K, Jacowski C, et al. Aedes aegypti: an emerging model for vector mosquito development. Cold Spring Harb Protoc. 2010;5(10):10.1101/pdb.emo141.

6. Huber K, Mousson L, Rodhain F, Failloux A. Isolation and variability of polymorphic microsatellite loci in Aedes aegypti, the vector of dengue viruses. Mol Ecol Notes. 2001;1:219-22.

7. Chambers EW, Meece JK, Mcgowan JA, Lovin DD, Hemme RR, Chadee DD, et al. Microsatellite isolation and linkage group identification in the yellow fever mosquito Aedes aegypti. J Hered. 2007:98:202-10.

8. Slotmam MA, Kelly NB, Harrington LC, Kitthawee S, Jones JW, Scott TW, et al. Polymorphic microsatellite markers for studies of Aedes aegypti (Diptera: Culicidae), the vector of dengue and yellow fever. Mol Ecol Notes. 2007;7: $168-71$.

9. Lovin DD, Washington KO, Debruyn B, Hemme RR, Mori A, Epstein SR, et al. Genome-based polymorphic microsatellite development and validation in the mosquito Aedes aegypti and application to population genetics in Haiti. BMC Genomics. 2009;10:590

10. Hickner PV, Debruyn B, Lovin DD, Mori A, Behura SK, Pinger R, Severson DW. Genome-based microsatellite development in the Culex pipiens complex and comparative microsatellite frequency with Aedes aegypti and Anopheles gambiae. PLoS One. 2010;5(9):e13062.

11. Soliani C, Rondan-Duenas J, Chiappero MB, Martínez M, García da Rosa E, Gardenal CN. Genetic relationships among populations of Aedes aegypti from Uruguay and northeastern Argentina inferred from ISSR-PCR data. Med Vet Entomol. 2010;24:316-23.

12. Hiragi C, Simões K, Martins E, Queiroz P, Lima L, Monnerat R. Variabilidade Genética em Populações de Aedes aegypti (L.) (Diptera: Culicidae) Utilizando Marcadores de RAPD. Neotrop Entomol. 2009;38:542-7.

13. Ravel S, Hervé JP, Diarrassouba S, Kone A, Cuny G. Microssatellite markers for population genetic studies in Aedes aegypti (Diptera: Culicidae) from Côte d'Ivoire: evidence for a microgeographic genetic differentiation of mosquitoes from Bouaké. Acta Trop. 2002;821:39-49. 
14. Endersby NM, Hoffmann AA, White VL, Lowenstein S, Ritchie S, Johnson PH, et al. Genetic structure of Aedes aegypti in Australia and Vietnam revealed by microsatellite and exon primed intron crossing markers suggestis feasibility of local control options. J Med Entomol. 2009:46:1074-83.

15. Olanratmanee P, Kittayapong P, Chansang C, Hoffmann AA, Weeks AR, Endersby NM. Population genetic structure of Aedes (Stegomyia) aegypti (L.) at a micro-spatial scale in Thailand: implications for a dengue suppression strategy. PLoS Negl Trop Dis. 2013;71:e1913.

16. Morlais I, Severson DW. Intraspecific DNA variation in nuclear genes of the mosquito Aedes aegypti. Insect Mol Biol. 2003;12:631-9.

17. Paduan KS, Ribolla PEM. Characterization of eight single nucleotide polymorphism markers in Aedes aegypti. Mol Ecol Resour. 2009;9:114-6.

18. IBGE Instituto Brasileiro de Geografia e Estatística. Estados. http://www.ibge. gov.br/estadosat/perfil.php?sigla=se. Accessed 14 Jun 2012

19. CEMESE/SEMARH - Centro Metereologia da Secretaria do Estado do Meio Ambiente e dos Recursos Hídricos 2012. Caracterização Climática. http:// www.semarh.se.gov.br/meteorologia/modules/tinyd0/index.php?id=45. Accessed 13 Jul 2012.

20. Ayres CFJ, Romão TPA, Melo-Santos MAV, Furtado AF. Genetic diversity in Brazilian population of Aedes albopictus. Mem Inst Oswaldo Cruz. 2002;97:871-5.

21. Peakall R, Smouse PE. GenALEx 6.5: genetic analysis in Excel. Population genetic software for teaching and research - an update. Bioinformatics. 2012;28:2537-9.

22. Pritchard JK, Stephens M, Donnelly P. Inference of population structure using multilocus genotype data. Genetics. 2000;155:945-59.

23. Jakobsson M, Rosenberg NA. CLUMPP: a cluster matching and permutation program for dealing with label switching and multimodality in analysis of population structure. Bioinformatics. 2007;23:1801-6.

24. Jombart T. Adegenet: a R package for the multivariate analysis of genetic markers. Bioinformatics. 2008:24:1403-5.

25. Olson-Manning C, Wagner MR, Mitchell-Olds T. Adaptive evolution: evaluating empirical support for theoretical predictions. Nat Rev Genet. 2012;13:867-77.

26. Schlötterer $\mathrm{C}$. Hitchhiking mapping-functional genomics from the population genetics perspective. Trends Genet. 2003;19:32-8.

27. SIRHSE - Sistema de Informações de Recursos Hídricos/Sergipe 2012. Clima. http://sirhse.semarh.se.gov.br/sirhse/index.php/macroplanejamento/bacias_ hidrograficas/estadoClima/estado. Accessed 13 Jul 2012.

28. Castro-Júnior FP, Martins WF, Lucena Filho ML, Almeida RP, Beserra EB. Ciclos de vida comparados de Aedes aegypti (Diptera: Culicidae) do semiárido da Paraíba. Iheringia Sér Zool. 2013;103:118-23.

29. Beserra EB, Fernandes CR, Silva SADO, Silva LAD, Santos JWD. Efeitos da temperatura no ciclo de vida, exigências térmicas e estimativas do número de gerações anuais de Aedes aegypti (Diptera, Culicidae). Iheringia Sér Zool. 2009;99:142-8

30. Valença MA, Marteis LS, Steffler LM, Silva AM, Santos RLC. Dynamics and characterization of Aedes aegypti (L.) (Diptera: Culicidae) key breeding sites. Neotrop Entomol. 2013;42:311-6.

31. Vitti JJ, Grossman SR, Sabeti PC. Detecting natural selection in genomic data. Annu Rev Genet. 2013;47:97-120.

32. Nielsen R. Molecular signatures of natural selection. Annu Rev Genet. 2005;39:197-218.

33. Jones CM, Liyanapathirana M, Agossa FR, Weetman D, Ranson H, Donnelly MJ, Wilding CS. Footprints of positive selection associated with a mutation (N1575Y) in the voltage-gated sodium channel of Anopheles gambiae. Proc Natl Acad Sci. 2012;109:6614-9.

34. Rose CJ, Chapman JR, Marshall SD, Lee SF, Batterham P, Ross HA Newcomb RD. Selective sweeps at the organophosphorus insecticide resistance locus, Rop-1, have affected variation across and beyond the a-esterase gene cluster in the Australian sheep blowfly, Lucilia cuprina. Mol Biol Evol. 2011;28:1835-46.

35. Urdaneta-Marquez L, Bosio C, Herrera F, Rubio-Palis Y, Salasek M, Black 4th WC. Genetic relationships among Aedes aegypti collections in Venezuela as determined by mitochondrial DNA variation and nuclear single nucleotide polymorphisms. Am J Trop Med Hyg. 2008;78:479-91.

36. Liu N. Insecticide resistance in mosquitoes: impact, mechanisms, and research directions. Annu Rev Entomol. 2015;60:537-59.

37. Aïzoun N, Aïkpon R, Akogbéto M. Evidence of increasing L1014F kdr mutation frequency in Anopheles gambiae s.l. pyrethroid resistant following a nationwide distribution of LLINs by the Beninese National Malaria Control Programme. Asian Pac J Trop Biomed. 2014;4:239-43.
38. Turner TL, Hahn MW. Locus-and population-specific selection and differentiation between incipient species of Anopheles gambiae. Mol Biol Evol. 2007;24:2132-8

39. Labbé $\mathrm{P}$, Sidos N, Raymond M, Lenormand T. Resistance gene replacement in the mosquito Culex pipiens: fitness estimation from long-term cline series. Genetics. 2009;182:303-12.

40. Omondi EO, Debener T, Linde M, Abukutsa-Onyango M, Dinssa FF, Winkelmann T. Molecular markers for genetic diversity studies in African leafy vegetables. Adv Biosci Biotechnol. 2016;7:188.

41. Hamblin MT, Warburton ML, Buckler ES. Empirical comparison of simple sequence repeats and single nucleotide polymorphisms in assessment of maize diversity and relatedness. PLoS One. 2007;2:e1367.

42. Bracco JE, Capurro ML, Lourenço-de-Oliveira R, Sallum MAM. Genetic variability of Aedes aegypti in the Americas using a mitochondrial gene: evidence of multiple introductions. Mem Inst Oswaldo Cruz. 2007;102:573-80.

43. Lima Jr RS, Scarpassa VM. Evidence of two lineages of the dengue vector Aedes aegypti in the Brazilian Amazon, based on mitochondrial DNA ND4 gene sequences. Genet Mol Biol. 2009;32:414-22.

44. Paduan KS, Araújo-Junior JP, Ribolla PEM. Genetic variability in geographical populations of Aedes aegypti (Diptera, Culicidae) in Brazil elucidated by molecular markers. Genet Mol Biol. 2006;29:391-5.

45. Damal K, Murrell EG, Juliano SA, Conn JE, Loew SS. Phylogeography of Aedes aegypti (Yellow Fever Mosquito) in South Florida: mtDNA evidence for human-aided dispersal. Am J Trop Med Hyg. 2013;89:482-8.

46. Rašić G, Endersby-Harshman N, Tantowijoyo W, Goundar A, White V, Yang $\mathrm{Q}$, et al. Aedes aegypti has spatially structured and seasonally stable populations in Yogyakarta, Indonesia. Parasit Vectors. 2015;8:610.

\section{Submit your next manuscript to BioMed Central and we will help you at every step:}

- We accept pre-submission inquiries

- Our selector tool helps you to find the most relevant journal

- We provide round the clock customer support

- Convenient online submission

- Thorough peer review

- Inclusion in PubMed and all major indexing services

- Maximum visibility for your research

Submit your manuscript at www.biomedcentral.com/submit
) Biomed Central 